\title{
Galacto-oligosaccharides production during lactose hydrolysis by free Aspergillus oryzae $\beta$-galactosidase and immobilized on magnetic polysiloxane-polyvinyl alcohol
}

\author{
David F.M. Neri ${ }^{a, b, *}$, Victor M. Balcão ${ }^{a, c}$, Rafael S. Costa ${ }^{a}$, Isabel C.A.P. Rocha ${ }^{a}$, Eugénio M.F.C. Ferreira ${ }^{a}$, \\ Duarte P.M. Torres ${ }^{a}$, Lígia R.M. Rodrigues ${ }^{a}$, Luiz B. Carvalho Jr. ${ }^{c}$, José A. Teixeira ${ }^{a}$ \\ a IBB-Institute for Biotechnology and Bioengineering, Centre of Biological Engineering, Universidade do Minho, Campus de Gualtar, P-4710-057 Braga, Portugal \\ ${ }^{\mathrm{b}}$ Departamento de Bioquímica and Laboratório de Imunopatologia Keizo Asami, Universidade Federal de Pernambuco, Brazil \\ ${ }^{\mathrm{C}}$ GIBQB-Grupo de Investigação em Bioengenharia e Química Biofarmacêutica, Universidade Fernando Pessoa, Rua Carlos da Maia no 296, P-4200-150 Porto, Portugal
}

\section{A R T I C L E I N F O}

\section{Article history:}

Received 10 August 2008

Received in revised form 7 October 2008

Accepted 19 November 2008

\section{Keywords:}

Galacto-oligosaccharides

Aspergillus oryzae

$\beta$-galactosidase

Covalent immobilization

Magnetic polysiloxane-polyvinyl alcohol

Mathematical modelling

\begin{abstract}
A B S T R A C T
The synthesis of galacto-oligosaccharides (GOS) by the action of Aspergillus oryzae $\beta$-galactosidase free and immobilized on magnetic polysiloxane-polyvinyl alcohol (mPOS-PVA) was studied. A maximum GOS concentration of $26 \%(\mathrm{w} / \mathrm{v})$ of total sugars was achieved at near $55 \%$ lactose conversion from $50 \%$, $\mathrm{w} / \mathrm{v}$ lactose solution at $\mathrm{pH} 4.5$ and $40{ }^{\circ} \mathrm{C}$. Trisaccharides accounted for more than $81 \%$ of the total GOS produced. GOS formation was not considerably affected by $\mathrm{pH}$ and temperature. The concentrations of glucose and galactose encountered near maximum GOS concentration greatly inhibited the reactions and reduced GOS yield. GOS formation was not affected by enzyme immobilization in the mPOS-PVA matrix, indicating the absence of diffusional limitations in the enzyme carrier. Furthermore, this water insoluble magnetic derivative was reutilized 10 -times and retained about $84 \%$ of the initial activity. In addition, the kinetic parameters for various initial lactose concentrations were determined and compared for the free and immobilized enzyme.
\end{abstract}

(c) 2008 Elsevier Ltd. All rights reserved.

\section{Introduction}

Galacto-oligosaccharides (GOS) are non-digestible food ingredients that beneficially affect the host by selectively stimulating the proliferation of bifidobacteria and lactobacilli in the intestine, which are considered to be beneficial to human health and can be synthesized from lactose when this sugar acts as the acceptor and transgalactosylation is catalyzed by $\beta$-galactosidase. However, if this acceptor is a water molecule galactose is released through a hydrolysis reaction (Sako, Matsumoto, \& Tanaka, 1999).

In aqueous systems transgalactosylation has to compete with hydrolysis, and therefore GOS mixtures always contain considerable amounts of remaining lactose and monosaccharides (Mahoney, 1998). Recently, $\beta$-galactosidase from Aspergillus oryzae was immobilized by three different techniques and used in oligosaccharides synthesis (Gaur, Pant, Jain, \& Khare, 2006).

Magnetic fields have been used in support systems for the study of enzyme immobilization (Bayramoglu, Yilmaz, Senel, \& Arica, 2008; Kuroiwa et al., 2008; Pimentel et al., 2007). The use of magnetic particles for enzyme immobilization in bioprocesses has

\footnotetext{
* Corresponding author. Address: IBB-Institute for Biotechnology and Bioengineering, Centre of Biological Engineering, Universidade do Minho, Campus de Gualtar, P-4710-057 Braga, Portugal. Tel.: +351 253604406; fax: +351 253678986.

E-mail addresses: davidfmneri@yahoo.com.br (D.F.M. Neri), lbcj@hotlink.com.br (L.B. Carvalho), jateixeira@deb.uminho.pt (J.A. Teixeira).
}

many advantages, as they can be used repeatedly and easily separated from the reaction medium by a magnetic field (Bruno, Coelho, Melo, \& Lima-Filho, 2005), reducing capital and operation costs (Pieters \& Bardeletti, 1992).

Michaelis-Menten kinetic parameters can be determined using graphical approaches or linear regression methods (Yang \& Okos, 1989; Ladero, Santos, Garcia, \& Garcia-Ochoa, 2001). Other methods use integrated rate equations by nonlinear regression to fit the model at different concentrations of substrate (Carrara \& Rubiolo, 1996). Most of the models have neglected the synthesis of oligosaccharides, however when using higher lactose concentrations the synthesis reactions are necessary to be included in the model. In order to give a good description of the experimental data a reaction mechanism that includes both hydrolysis and synthesis was used. To better describe the process, a kinetic model was adapted from the work of Boon, Janssen, and van der Padt (1999).

Although $\beta$-galactosidase is the most employed enzyme for the industrial production of GOS, kinetics studies considering the hydrolysis of lactose and oligosaccharides synthesis by these enzymes are limited (Bruins, Strubel, van Lieshout, Janssen, \& Boom, 2003) and most of the works in the literature consider only the hydrolysis reaction (Aslan \& Tanriseven, 2007; Nakkharat \& Haltrich, 2006). The aim of this work was to study lactose hydrolysis and oligosaccharides synthesis by $\beta$-galactosidase from $A$. oryzae free and covalently immobilized on magnetic polysiloxanepolyvinyl alcohol (mPOS-PVA) particles at various initial lactose 
concentrations, different temperatures and $\mathrm{pH}$. In addition, the kinetic parameters for various initial lactose concentrations (10$50 \%$; w/v) were determined and compared for the free and immobilized enzyme by using experimental data.

\section{Materials and methods}

\subsection{POS-PVA synthesis and magnetization}

POS-PVA beads were synthesized according to the procedure described by Barros, Almeida, Carvalho, and Azevedo (2002). Briefly: $6 \mathrm{ml}$ of $2 \%(\mathrm{w} / \mathrm{v})$ polyvinyl alcohol, $5 \mathrm{ml}$ of ethanol and $5 \mathrm{ml}$ of tetraethylorthosilicate (TEOS) were mixed in a beaker. After heating up to $100{ }^{\circ} \mathrm{C}$, under magnetic stirring, $100 \mu \mathrm{l}$ of concentrated $\mathrm{HCl}$ were added and the mixture incubated for an extra $50 \mathrm{~min}$. Subsequently, the solution was distributed into the wells of ELISA microplates ( $200 \mu \mathrm{l}$ per well) and allowed to solidify for ca. $48 \mathrm{~h}$ at $25^{\circ} \mathrm{C}$. The resulting beads were smashed using a mortar and pestle; the powder $(2 \mathrm{~g})$ suspended in deionized water $(100 \mathrm{ml})$ and $10 \mathrm{ml}$ of a solution containing $0.6 \mathrm{M} \mathrm{FeCl}_{2}$ and $1.1 \mathrm{M} \mathrm{FeCl}_{3}$ (1:1) were added dropwise under magnetic stirring. Afterwards, the $\mathrm{pH}$ and temperature were adjusted, under overhead stirring, to 11.0 (using 33\%, w/v, $\mathrm{NH}_{4} \mathrm{OH}$ ) and $100{ }^{\circ} \mathrm{C}$, respectively, followed by incubation for $30 \mathrm{~min}$. The resulting magnetized particles were thoroughly washed with deionized water until $\mathrm{pH}$ 7.0 was reached (Carneiro-Leão, Oliveira, \& Carvalho, 1991) and the magnetic particles collected by using a magnetic field (Ciba Corning; $6000 \mathrm{Oe}$ ). The washed magnetic POS-PVA particles were dried at $50^{\circ} \mathrm{C}$ overnight and finally sieved $(<100 \mu \mathrm{m})$.

\section{2. $\beta$-galactosidase immobilization}

For activation of the support, $10 \mathrm{mg}$ of magnetized particles were incubated in $2.5 \%(\mathrm{v} / \mathrm{v})$ glutaraldehyde $(1 \mathrm{ml})$ in $9 \mathrm{ml}$ of $0.1 \mathrm{M} \mathrm{H}_{2} \mathrm{SO}_{4}$ under orbital stirring $(20 \mathrm{rpm})$ for $2 \mathrm{~h}$ at $25^{\circ} \mathrm{C}$. Following this incubation period, the particles were washed five times with $20 \mathrm{mM}$ citrate-phosphate buffer, $\mathrm{pH}$ 4.5. The glutaraldehyde-activated POS-PVA magnetized particles $(10 \mathrm{mg})$ were incubated with $1 \mathrm{ml} \quad \beta$-galactosidase solution at different concentrations in the same buffer, for $18 \mathrm{~h}$ at $4{ }^{\circ} \mathrm{C}$ and $20 \mathrm{rpm}$. The enzymatic derivative thus produced was collected and washed five times with the aforementioned citrate-phosphate buffer. The immobilized enzyme was kept in the buffer at $4{ }^{\circ} \mathrm{C}$ until use and both the supernatant and washes were used for protein determination. The protein concentration was determined according to the method described by Smith et al. (1985) using bovine serum albumin as standard. The amount of immobilized protein was calculated by the difference between the amount of protein offered to the support for immobilization and that found in the supernatant and the washing buffers.

\subsection{Galacto-oligosaccharides production}

Production of GOSs from lactose was studied with free and immobilized enzyme on mPOS-PVA in different conditions. The reaction kinetics was studied at six different initial lactose concentrations $(5,10,20,30,40$, and $50 \%, w / v)$, five different $\mathrm{pH}$ values $(3.5,4.0,4.5,5.0$, and 5.5$)$, and four different temperatures (30, 40,50 , and $60^{\circ} \mathrm{C}$ ). The lactose solution was prepared by dissolving lactose in $20 \mathrm{mM}$ citrate-phosphate buffer solution. Samples were taken at appropriate time intervals and analyzed for sugar content by high performance liquid chromatography (HPLC). The effects of galactose and glucose on GOSs production were also studied by adding galactose $(3,7$, and $10 \%, w / v)$ and/or glucose $(3,7$, and $10 \%, \mathrm{w} / \mathrm{v}$ ) in the lactose solution.

\subsection{Sugar analysis}

GOSs, lactose, glucose and galactose concentration were determined using HPLC (Jasco AS-2057 Plus), with a MetaCarb $67 \mathrm{H}$ at $60{ }^{\circ} \mathrm{C}$ column and refractive index detector (Jasco RI-2031 Plus); used mobile phase was a $0.001 \mathrm{~N} \mathrm{H}_{2} \mathrm{SO}_{4}$ solution at a flow rate of $0.5 \mathrm{ml} \mathrm{min}^{-1}$. As the concentration $(\mathrm{w} / \mathrm{v})$ of these sugars is proportional to their peak areas, normalized sugar concentrations as weight percentages of total sugars or initial lactose were determined from peak areas and are reported in this work. It should be noted that the accuracy of this approximation was verified by checking the material balance. It is possible that the lactose peak shown in the chromatogram might also contain other disaccharides, although it has been reported that the extent of disaccharide formation is limited with this enzyme as compared with other lactases (Albayrak \& Yang, 2002; Dombo, Yamamoto, \& Nakajima, 1997).

\subsection{Determination of kinetic parameters and data handling}

The presented kinetic model for the trisaccharides synthesis and lactose hydrolysis mechanisms includes glucose and galactose competitive inhibition and was mathematically modelled following four ordinary differential equations:

The lactose hydrolysis $(L)$ is given by,

$\frac{\mathrm{d} L}{\mathrm{~d} t}=\frac{n_{1 L}[L]\left[\mathrm{H}_{2} \mathrm{O}\right]+n_{2 L}[\operatorname{Tri}]\left[\mathrm{H}_{2} \mathrm{O}\right]+n_{3 L}[L]^{2}}{d_{1}}$ where,

$n_{1 L}=\frac{-k_{1} k_{2}}{k_{4}} ; \quad n_{2 L}=k_{2} ; \quad n_{3 L}=\frac{-2 k_{1} k_{3}}{k_{4}}$

the glucose $(G)$ formation by,

$\frac{\mathrm{d} G}{\mathrm{~d} t}=\frac{n_{1 G}[L]^{2}+n_{2 G}[L]\left[\mathrm{H}_{2} \mathrm{O}\right]}{d_{1}} \quad$ where, $\quad n_{1 G}=\frac{k_{1} k_{3}}{k_{4}} ; \quad n_{2 G}=\frac{k_{1} k_{2}}{k_{4}}$

and the galactose ( $\mathrm{Gal}$ ) by,

$$
\begin{array}{ll}
\frac{\mathrm{dGal}}{\mathrm{d} t}=\frac{n_{1 \text { Gal }}\left[\mathrm{H}_{2} \mathrm{O}\right][L]+n_{2 \text { Gal }}[\text { Tri }]\left[\mathrm{H}_{2} \mathrm{O}\right]}{d_{1}} & \text { where, } \\
n_{1 \text { Gal }}=\frac{k_{1} k_{2}}{k_{4}} ; \quad n_{2 \text { Gal }}=k_{2} &
\end{array}
$$

Finally, the trisaccharides production (Tri) is described by the Eq. (4)

$$
\begin{aligned}
& \begin{aligned}
\frac{\mathrm{d} T r i}{\mathrm{~d} t} & =\frac{n_{1 T r i}[\operatorname{Tri}]\left[\mathrm{H}_{2} \mathrm{O}\right]+n_{2 T r i}[L]^{2}}{d_{1}} \text { with, } \\
n_{1 T r i} & =-k_{2} ; n_{2 T r i}=\frac{k_{1} k_{3}}{k_{4}} \text { and } \\
d_{1}= & \frac{k_{2}}{k_{4}}\left[\mathrm{H}_{2} \mathrm{O}\right]+\left(\frac{k_{3}}{k_{4}}+\frac{k_{1}}{k_{4}}\right)[L]+[\text { Tri }]+\frac{k_{2} k_{5}}{k_{4} k_{6}}[G]\left[\mathrm{H}_{2} \mathrm{O}\right]+\frac{k_{3} k_{7}}{k_{4} k_{8}}[\mathrm{Gal}][L] \\
& +\frac{k_{2} k_{7}}{k_{4} k_{8}}[\mathrm{Gal}]\left[\mathrm{H}_{2} \mathrm{O}\right]+\frac{k_{3} k_{5}}{k_{4} k_{6}}[G][L]
\end{aligned}
\end{aligned}
$$

where $k_{1}, k_{2}, k_{3}, k_{4}, k_{5}, k_{6}, k_{7}$ and $k_{8}$ are reaction rate constants. The kinetic model was adapted from the work of Boon et al. (1999) and the rate expressions were derived with the King-Altman method (King \& Altman, 1956).

The model described (Eqs. (1)-(4)) consists of a set of four differential equations thus representing four dependent state variables (lactose, glucose, galactose and trisaccharides concentration) and up to eight parameters $\left(k_{1}, k_{2}, k_{3}, k_{4}, k_{5}, k_{6}, k_{7}\right.$ and $\left.k_{8}\right)$. In this model water or lactose can react with the galactosyl-enzyme complex and the synthesis of the oligosaccharides is assumed to be reversible. The model used only lactose as substrate. Lactose inhibition, formation of allolactose (Huber, Kurz, \& Wallenfels, 1976), mutarotation of galactose (Bakken, Hill, \& Amundson, 1992), 


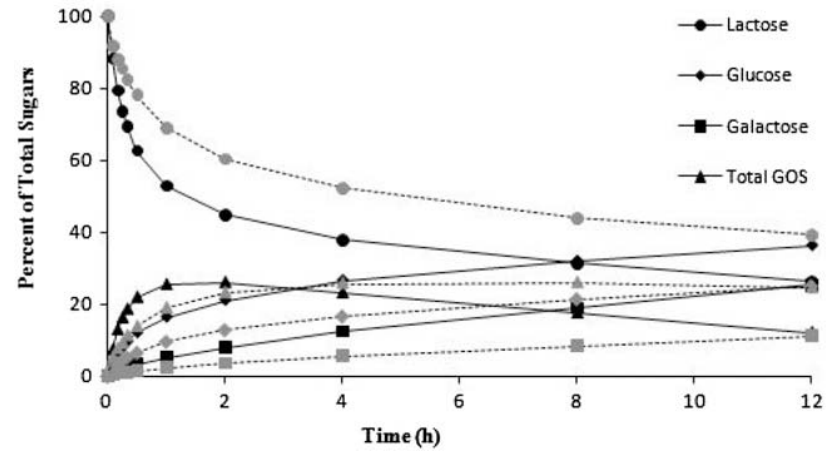

Fig. 1. Lactose $(50 \%, w / v)$ hydrolysis by free (grey symbol) and immobilized (black symbol) A. oryzae $\beta$-galactosidase on mPOS-PVA at $\mathrm{pH} 4.5$ and $40^{\circ} \mathrm{C}$. Total GOS, galactose and glucose production were estimated by HPLC.

formation of tetra-saccharides, diffusional limitations and enzyme inactivation with time were not considered in the model. Also, eventual temperature and $\mathrm{pH}$ effects on the lactose hydrolysis and oligosaccharides synthesis were not included.
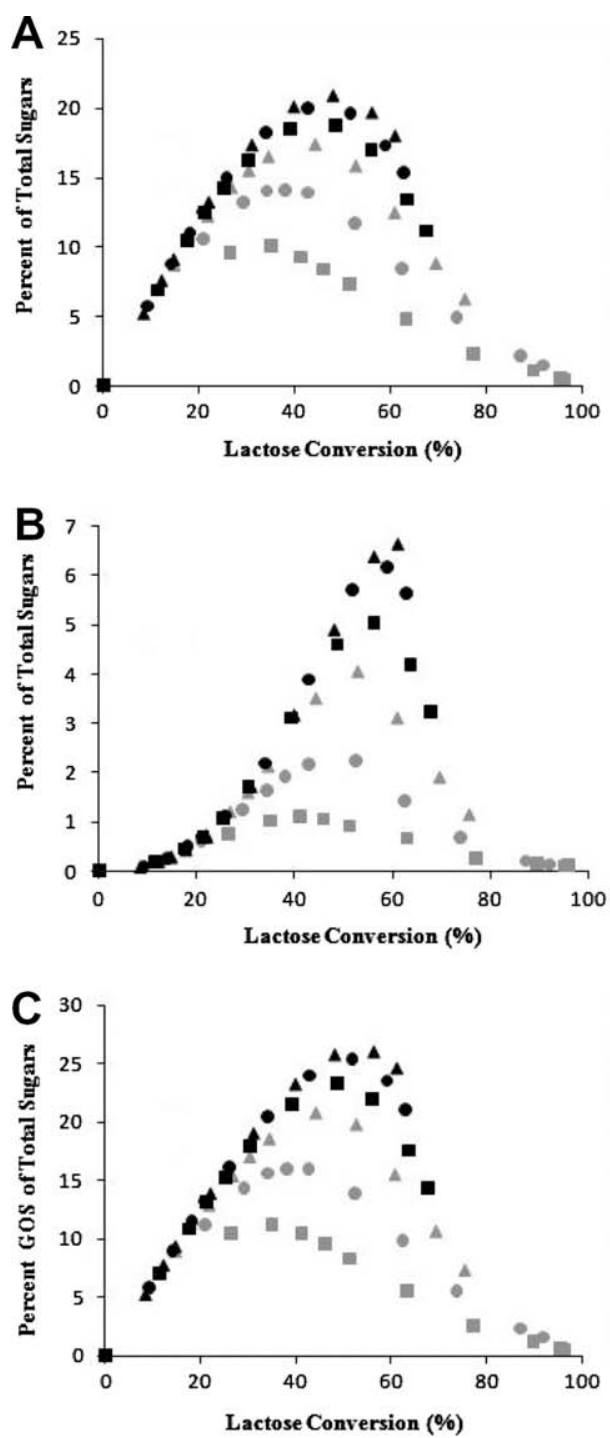

Initial values for the state variables were taken from the experimental data and their concentrations were analyzed off-line. The estimation of the model parameters were performed by the simulated annealing algorithm of the systems biology toolbox for Matlab (Mathworks) software (Schmidt \& Jirstrand, 2006) using the results of the independent batch experiments, with the sets of experimental data from different initial lactose concentration $(10-50 \% ; \mathrm{w} / \mathrm{v})$ as substrate. All experimental data points were fitted simultaneously for each concentration. According to the model above mentioned the eight rate constants were as follows: $k_{1}$ is the overall reaction rate constant; $k_{2}$, describes the reaction of water with the galactosyl-enzyme complex; $k_{3}$ is a measure of oligosaccharides synthesis; $k_{4}$ describes the hydrolysis of the formed oligosaccharides; and $k_{5} / k_{6}$ and $k_{7} / k_{8}$ account for glucose and galactose inhibition, respectively. The eight parameters were grouped into five parameters $\left(k_{1}, k_{4}, k_{3} / k_{4}, k_{5} / k_{6}\right.$ and $\left.k_{7} / k_{8}\right)$ that were estimated and $k_{2}$, which was assumed constant. The rate equations were applied in the program, taking into account product galactose inhibition with $\left(k_{7}, k_{8} \neq 0\right)$ and without $\left(k_{5}, k_{6}=0\right)$ glucose inhibition. The ordinary differential equations from the model were solved by numerical integration with an ODE23s method which is also offered in the same software.
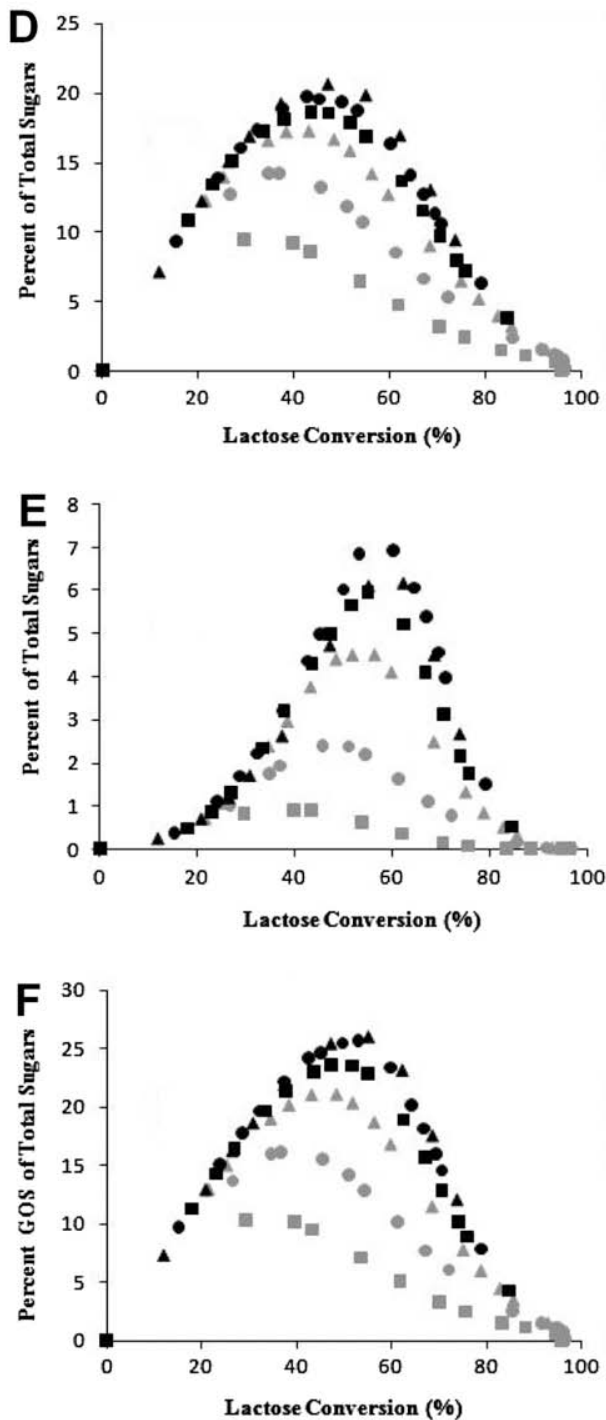

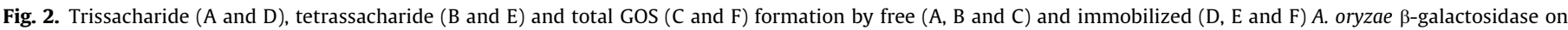

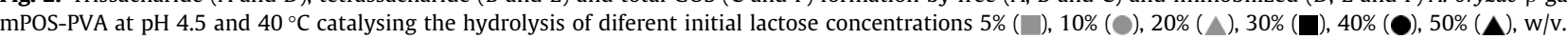




\section{Results and discussion}

3.1. Effects of lactose concentration on GOS production by free and immobilized enzyme

The most significant factor on GOS formation is the initial lactose concentration (Boon, Janssen, \& van der Padt, 2000). A typical GOS, glucose and galactose time course production is presented in Fig. 1 for $50 \%$, w/v intial lactose concentration, for free and immobilized $A$. oryzae $\beta$-galactosidase. From this, it can be observed that: (1) the mass amount of consumed lactose equals the mass amount of GOS plus the monosaccharides mass amount, (2) different conversion rates were observed for free and immobilized enzyme experiments; this is a consequence of the different amounts of enzymes being used (an enzyme concentration of $0.149 \mathrm{mg} / \mathrm{ml}$ was used in the free form, while for the immobilized form, enzyme concentration was $0.383 \mathrm{mg} / \mathrm{ml}$ ).

Similar experiments were performed for different initial lactose concentrations $(5-40 \%, \mathrm{w} / \mathrm{v})$ and the tri- and the tetra-saccharides produced (expressed as percent of total sugars) were plotted against the percent of hydrolyzed lactose (Fig. 2).

Fig. 2 shows that GOS (tri- and tetra-saccharides) production increased with increasing lactose concentration. However, for each lactose concentration the GOS production decreased after a certain degree of lactose conversion. This can be attributed to a preferential hydrolysis (formation of glucose and galactose) rather than GOS synthesis. Comparing Fig. $2 \mathrm{~A}$ and $2 \mathrm{~B}$ one can notice that the trisaccharide production is higher (about $21 \%$ of total sugars for $50 \%, w / v$, of lactose) than the tetra-saccharide (about $7 \%$ of total sugars for $40 \%, w / v$, lactose). Furthermore, there was no marked difference between the free and immobilized enzyme performances. As the initial lactose concentration increased from $5 \%$ to $50 \%$, the maximum GOS content in the product increased from $11.2 \%$ (at $35 \%$ conversion) to $26.1 \%$ (at $56 \%$ conversion) for the free enzyme and from $10.4 \%$ (at $30 \%$ conversion) to $26.0 \%$ (at $55 \%$ conversion) for the immobilized enzyme. The maximum amount of tri-, tetra-saccharides and total GOS obtained for the immobilized enzyme were $103.4 \mathrm{gl}^{-1}, 30.8 \mathrm{~g} \mathrm{l}^{-1}$ and $129.9 \mathrm{~g} \mathrm{l}^{-1}$ for a lactose conversion of about $47 \%, 62 \%$, and $55 \%$, respectively, in $500 \mathrm{~g} \mathrm{l}^{-1}$ of lactose. For the free enzyme, the corresponding values of $104.5 \mathrm{~g} \mathrm{l}^{-1}$, $33.2 \mathrm{~g} \mathrm{l}^{-1}$ and $130.3 \mathrm{~g} \mathrm{l}^{-1}$ were obtained for about $48 \%, 61 \%$ and $56 \%$ lactose conversion, respectively in $500 \mathrm{~g} \mathrm{l}^{-1}$ of lactose. As expected, considering the small size of the particles, these results confirm that enzyme immobilization on mPOS-PVA does not impose any mass transfer limitations on GOS formation from lactose. Similar results were obtained with $\beta$-galactosidase from A. oryzae immobilized on cotton cloth (Albayrak \& Yang, 2002). Higher operational and thermal stability, making possible its reuse, has been demonstrated to be one of the advantages of this system for enzyme immobilization (Neri, Balcão, Carneiroda-Cunha, Carvalho, \& Teixeira, 2008). An immobilized $\beta$-galactosidase on mPOS-PVA preparation acting on $20 \%(\mathrm{w} / \mathrm{v})$ lactose was successively reutilized for 10 cycles at $25^{\circ} \mathrm{C}$ and at the end the enzymatic derivative retained approximately $84 \%$ of its initial activity (data not shown), confirming the advantages of the mPOS-PVA $\beta$-galactosidase derivative. Similar results were previously reported (Neri et al., 2008) using this support for the immobilization of Kluyveromyces lactis $\beta$-galactosidase acting on a synthetic substrate (ONPG; ortho-nitrophenyl-b-D-galactopyranoside), as after 20 reutilization cycles the immobilized enzyme re-
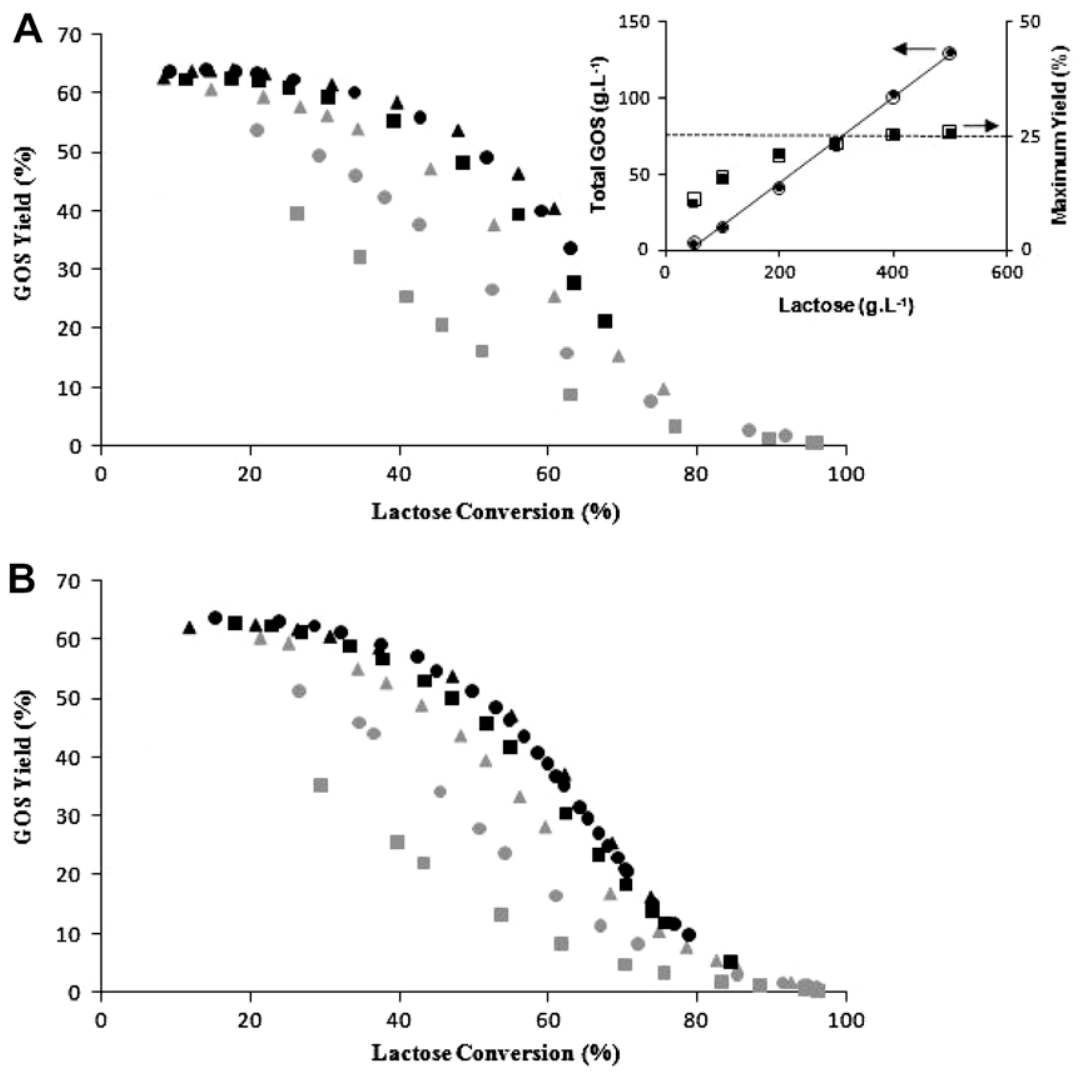

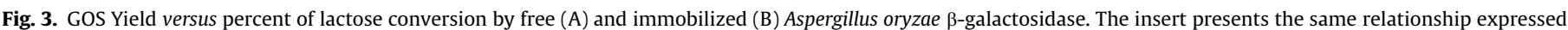

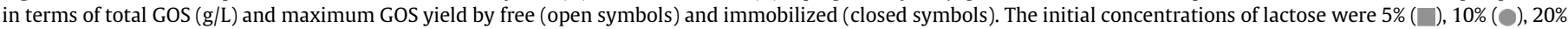

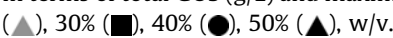


tained about 50\% of the initial activity. Apart from this, the easy separation of the MPOS-PVA preparation from the reaction medium by the action of a magnetic field must be pointed out.
GOS yields during lactose hydrolysis catalyzed by the free and the immobilized $\beta$-galactosidase on mPOS-PVA are shown in Fig. 3. The maximum GOS yield increased with the initial lactose
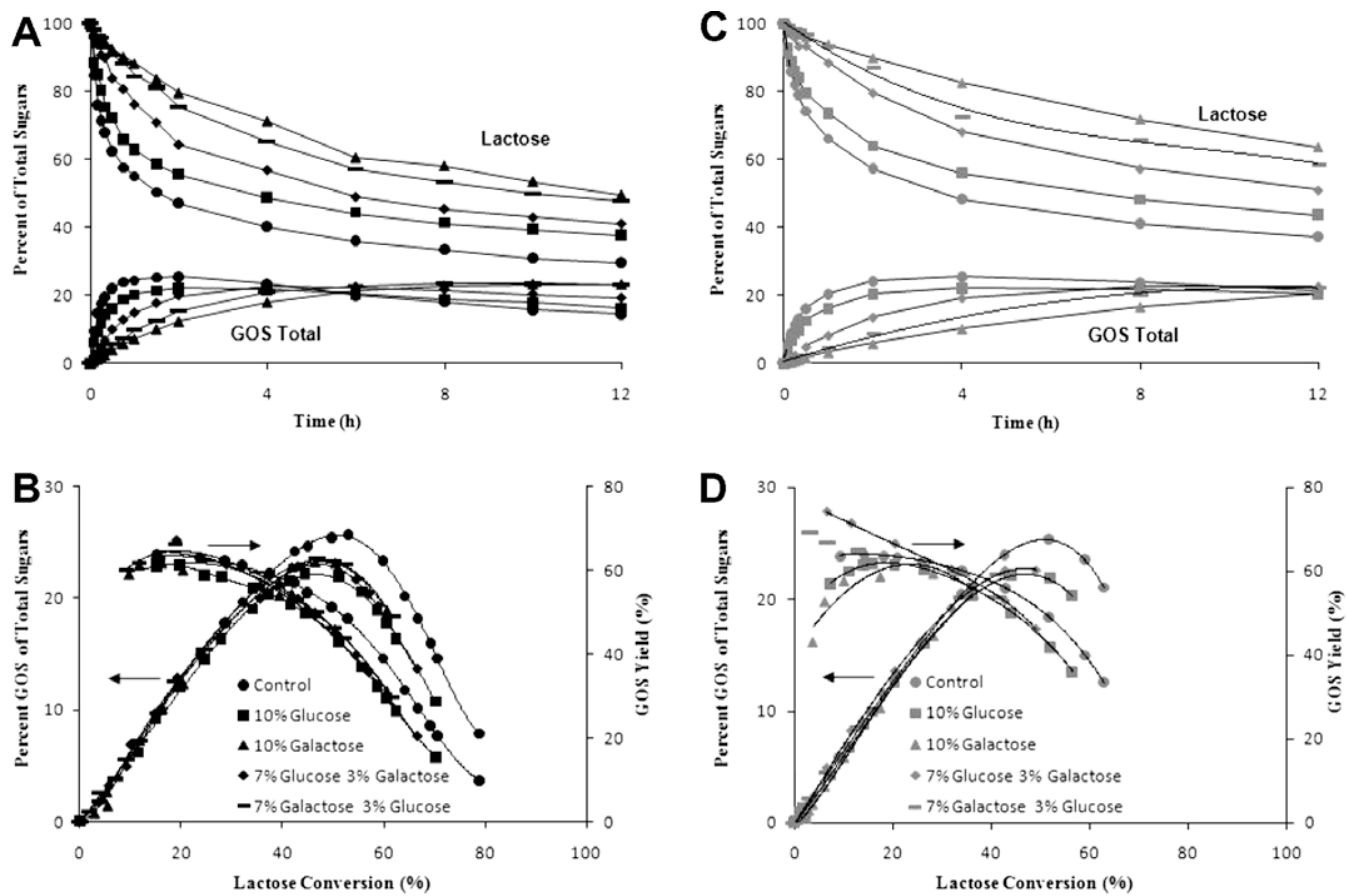

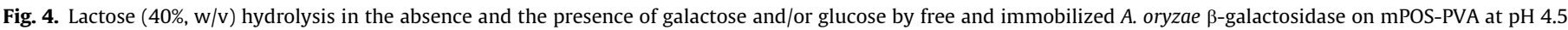

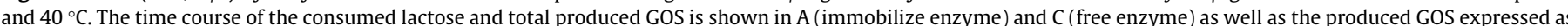
percent of total sugars and yield versus lactose conversion for the immobilized (B) and free (D) enzyme.
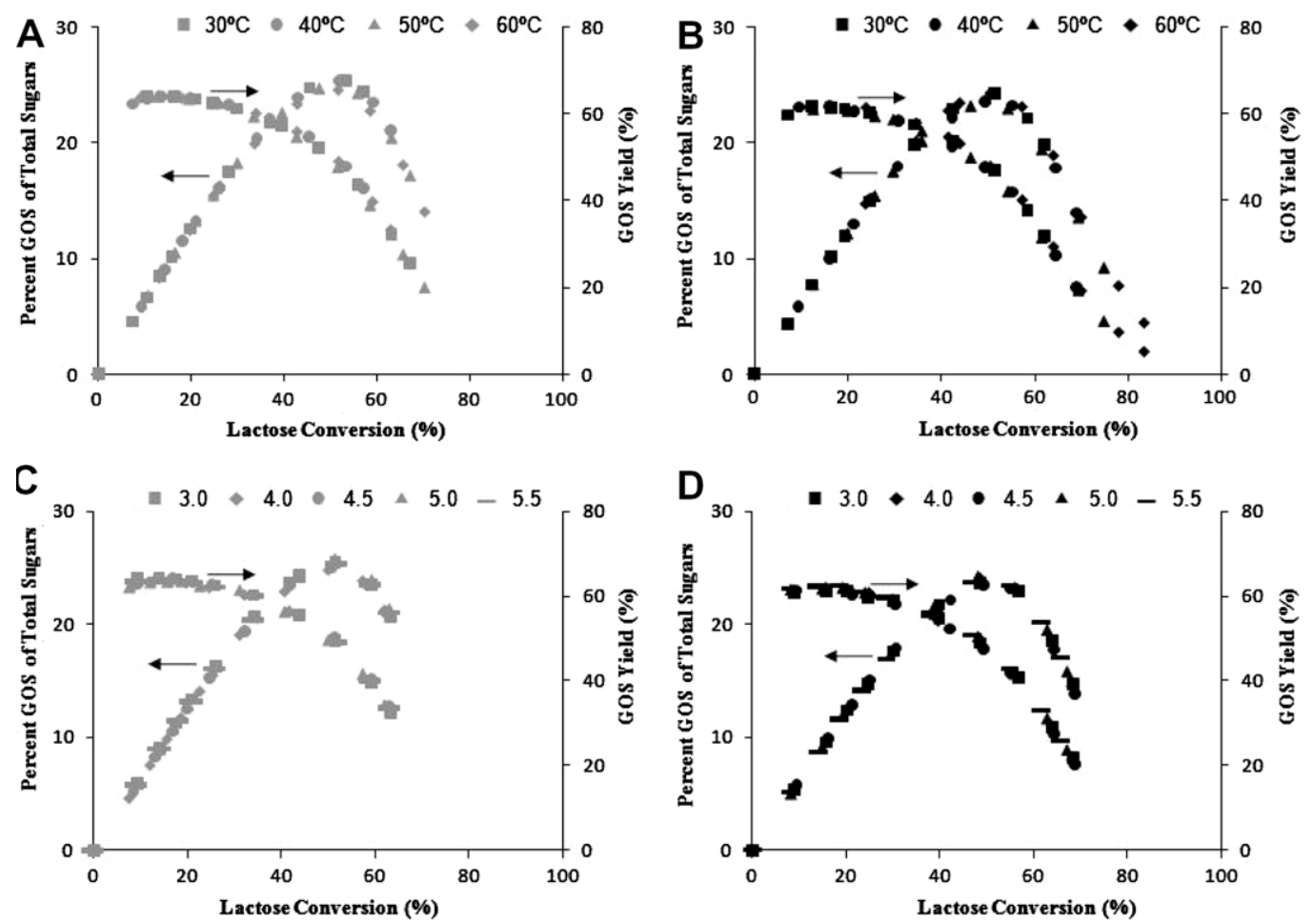

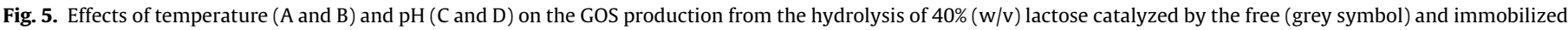
(black symbol) $A$.oryzae $\beta$-galactosidase on m-POS-PVA. 
concentration for both enzyme preparations The maximal values ranged from $39.5 \%(5 \%, \mathrm{w} / \mathrm{v}$, lactose) to $64.1 \%$ (higher lactose concentrations) for the free enzyme and from $35.2 \%(5 \%, \mathrm{w} / \mathrm{v}$, lactose) to $62.6 \%$ (higher lactose concentrations) for the immobilized one. It was observed that the hydrolysis and transgalactosylation reactions occurred simultaneously and that the product profile of the reaction is largely dependent on lactose concentration. The hydrolysis reaction dominates at low lactose concentration while GOS formation dominates at high lactose concentrations. $\beta$-Galactosyl groups should have a higher probability of attaching to lactose than water at increasing lactose concentrations (Iwasaki, Nakajima, \& Nakao, 1996). The insert of Fig. 3 presents these same data in a different way, cleary demonstrating that an increase in lactose concentration leads to an increase in GOS production. However, in terms of GOS yield, an increase was observed up to $300 \mathrm{~g} \mathrm{l}^{-1}$ of initial lactose concentration, while for higher lactose concentrations the GOS yield was almost constant at $23.5-26 \%$ for both free and immobilized enzyme. Park, Kim, Lee, Kim, and Oh (2007) observed the same behavior for high lactose concentration with a thermostable $\beta$-galactosidase from Sulfolobus solfataricus.

It is possible that some disaccharides such as allolactose and galactobiose are formed by the enzymatic transfer of galactose to glucose and galactose, respectively. The absence of this side reactions, were confirmed by checking the molar balances of glucose and galactose over the course of the reaction, assuming that all GOS only contained one unit of glucose with galactose as the remaining sugar. It is also possible that different trisaccharides were also formed, but were not detected by HPLC.

\subsection{Effects of galactose and glucose}

Galactose is well known as a competitive inhibitor to the lactose hydrolysis reaction (Bakken, Hill, \& Amundson, 1991; Portaccio et al., 1998; Shukla \& Chaplin, 1993). From a thermodynamic point of view, a high galactose (product) concentration could favour the reversed hydrolysis reaction and cause an equilibrium shift towards condensation, thereby increasing GOS yield. How- ever, the effects of monosaccharides on GOS formation rate and product yield have not been well characterized. Thus, the possible effect of monosaccharides on GOS formation was investigated by adding galactose and/or glucose into the initial lactose solution, both for free and immobilized enzyme (Fig. 4). As expected, the reaction rate markedly decreased in the presence of galactose for both immobilized enzyme (Fig. 4A) and free enzyme (Fig. 4B). It is also shown that the addition of glucose either alone or mixed with galactose, simultaneously decreased lactose hydrolysis and GOS formation, indicating a different mechanism of action of glucose on the reaction kinetics glucose did not act as an inhibitor to A. oryzae $\beta$-galactosidase and acted as a non-competitive inhibitor for some bacterial (Shin \& Yang, 1998) and yeast enzymes (Cavaille \& Combes, 1995). Overall, it is clear that the monosaccharides negatively affected the GOS formation from lactose by $\beta$-galactosidase. Hansson et al. (2001) reported that GOS formation by $\beta$-galactosidase action was more of a kinetically controlled transgalactosylation reaction rather than reversed hydrolysis. Reversed hydrolysis or condensation may occur at high concentrations of monosaccharides upon prolonged incubations. Thus, it can be concluded that free glucose and galactose are not recommended for GOS formation and should be removed from the reaction mixture in order to increase GOS yield and formation rate.

\subsection{Effects of temperature and $\mathrm{pH}$}

Temperature and $\mathrm{pH}$ normally have a pronounced effect on the enzyme reaction rates but showed to have a minimal effect, if any, on GOS production (Albayrak \& Yang, 2002; Iwasaki et al., 1996; Monsan \& Paul, 1995). As shown in Fig. 5, GOS production was almost unchanged despite temperatures varying from $30^{\circ} \mathrm{C}$ to $60^{\circ} \mathrm{C}$ (Fig. 5A and 5B) and pH from 3.5 to 5.5 (Fig. 5C and 5D) for the conversion of $40 \%(\mathrm{w} / \mathrm{v})$ lactose, for both the free and immobilized enzyme preparations. Albayrak and Yang (2002) reported similar results for $\beta$-galactosidase from $A$. oryzae immobilized on cotton cloth.
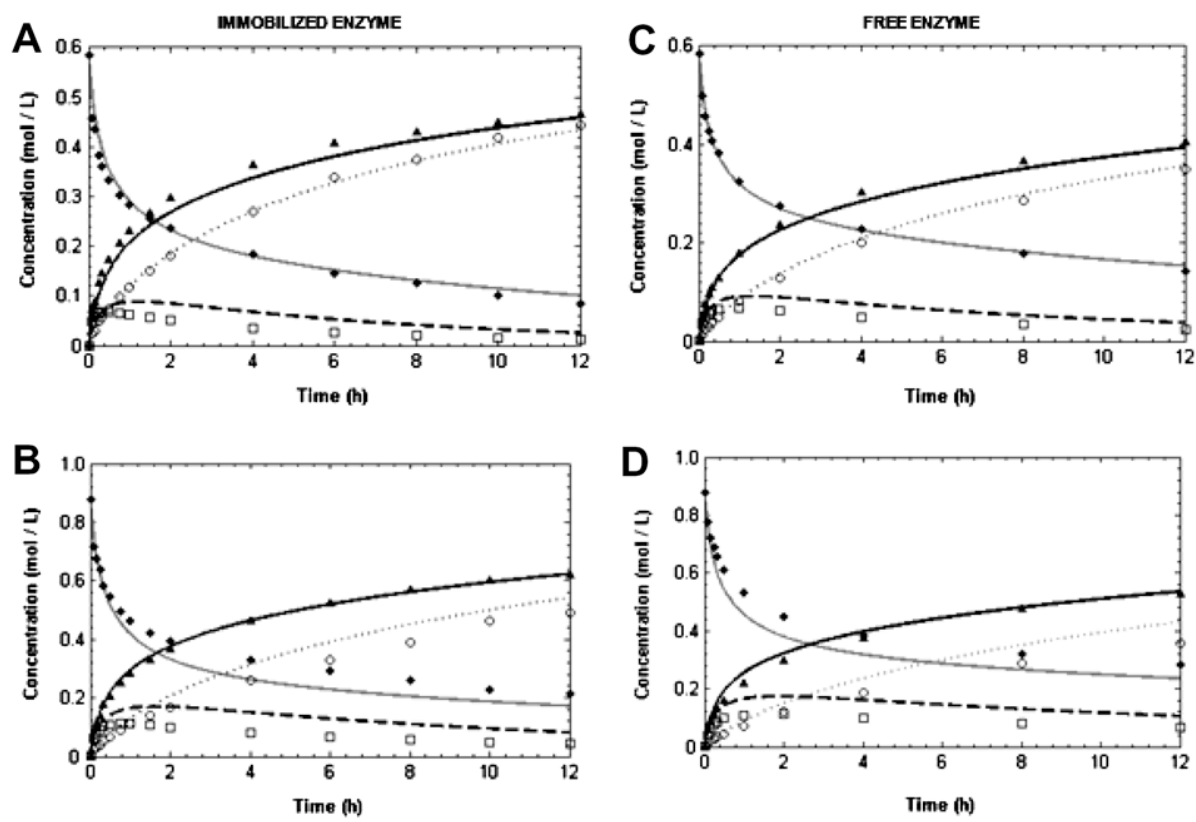

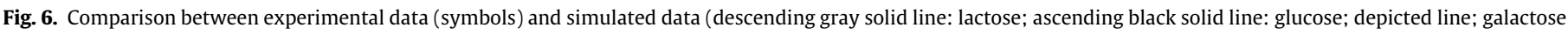

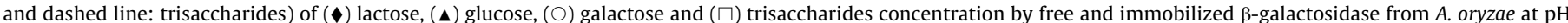

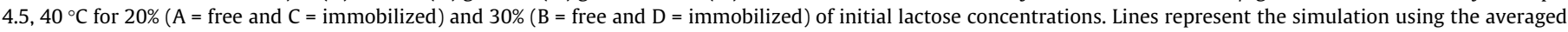
kinetic parameters of all fittings. 
Table 1

Estimated average values and confidence intervals of parameters for the free and immobilized $\beta$-galactosidase, obtained by fitting the experimental data for $A$. oryzae at different initial lactose concentration (10-50\%).

\begin{tabular}{lll}
\hline Parameter (units) & Immobilized & Free \\
\hline$k_{1}\left(\mathrm{~h}^{-1}\right)$ & $1.41 \pm 0.75$ & $1.16 \pm 0.92$ \\
$k_{3} / k_{4}, \log \left(k_{3} / \mathrm{k} 4\right)(-)$ & $37.15,1.57 \pm 0.26$ & $39.08,1.59 \pm 0.049$ \\
$k_{4}\left(\mathrm{~h}^{-1}\right)$ & $4.78 \pm 0.35$ & $10.50 \pm 5.84$ \\
$k_{7} / k_{8}, \log \left(k_{7} / \mathrm{k} 8\right)(-)$ & $32.36,1.51 \pm 0.12$ & $51.29,1.71 \pm 0.19$ \\
\hline
\end{tabular}

\subsection{Kinetic analysis of free and immobilized enzyme}

To verify the precondition that the model parameters are independent of the initial lactose concentrations, the 95\% confidence interval of the slope of the linear dependence of the kinetic parameters on initial lactose concentration was estimated (data not shown) as, to determine one parameter set for various initial lactose concentrations by taking average parameters values, the estimated parameters have to be independent of the initial lactose concentration. Dependency of the parameters on the initial lactose concentration was observed for the free enzyme and $\log \left(k_{3} / k_{4}\right)$ for the immobilized enzyme. However, the averaged parameter values for the free and immobilized enzyme were used.

Results presented in Fig. 4 show that single, galactose addition was found to have the more pronounced inhibition effect on $\beta$ galactosidase activity. These results have also been found in a previous study (Friend \& Shahani, 1982). In addition, enzyme inhibition by glucose plus galactose has also been observed, but only the galactose inhibition effect was included in the considered models in this study $\left(k_{5}, k_{6}=0\right.$ and $\left.k_{7}, k_{8} \neq 0\right)$.

Fig. 6 show a comparison of the experimental and calculated concentrations profiles with the averaged parameters (examples for 20 and 30\% initial lactose concentrations) obtained for free and immobilized enzyme respectively. The kinetic model was validated by comparing the set of experimental data from the $\beta$-galactosidase to data obtained by model simulation with different initial lactose concentrations ranging from 10 to $50 \%$ (w/v). To determine the effect of the immobilization process on the kinetic parameters, in other words, on lactose hydrolysis and trisaccharides synthesis, experiments were carried out at various initial lactose concentrations. The good fitting quality of the model to the free enzyme and especially to the immobilized enzyme is remarkable for all initial lactose concentrations studied. The model accurately describes the time course lactose conversion and glucose formation with time, but only provides a reasonable fit for the trisaccharides production and galactose as shown in Fig. 6. The production of trisaccharides and galactose is slightly overestimated.

The parameter $k_{3}$, that regulates the oligosaccharides synthesis and $k_{4}$, which regulates the hydrolysis of the formed oligosaccharides are assumed to be key parameters in the overall process. Not surprisingly, as can be observed in Table 1, the ratio between $k_{3}$ and $k_{4}$ is of the same order of magnitude for both free and immobilized enzyme, indicating that the relative extent of the synthesis and hydrolysis reactions is not affected by the immobilization procedure. This is in accordance with the obtained experimental data.

\section{Conclusions}

Magnetic polysiloxane-polyvinyl alcohol proved to be an adequate support for $A$. oryzae $\beta$-galactosidase immobilization and its use on GOS production using lactose as substrate.

The initial lactose concentration in the reaction media affected the total amounts of produced galacto-oligosaccharides and their time course production was described as a "bell-shaped" curve as a result of the balance between transgalactosylation and hydrolysis. The galacto-oligosaccharides formation ability of the enzyme was not affected by its immobilization onto magnetic polysiloxane-polyvinyl alcohol, a support that can be easily recovered by applying a magnetic field and that made possible to retain $84 \%$ of the enzyme initial activity after 10 utilization cycles. The addition of galactose either alone or mixed to glucose decreased the lactose hydrolysis and galacto-oligosaccharides formation. The galacto-oligosaccharides production was almost unchanged despite temperatures varying from $30^{\circ} \mathrm{C}$ to $60^{\circ} \mathrm{C}$ and $\mathrm{pH}$ from 3.5 to 5.5 both for the free and immobilized enzyme preparations. A model that adequately describes oligosaccharides production by the enzyme (free and immobilized) including galactose inhibition was successful used. Analysis of the model parameters shows that the more relevant parameters are those involved in the galactose-enzyme complex formation and those involved in the trisaccharides synthesis and hydrolysis. The model describes the experimental data well in the range of the initial lactose concentration used.

\section{Acknowledgments}

David F. M. Neri gratefully acknowledges support by the Programme Alßan, the European Union Programme of High Level Scholarships for Latin America (Scholarship No. E05D057787BR). Luiz B. Carvalho Jr. is recipient of a scholarship of the Brazilian National Research Council (CNPq).

\section{References}

Albayrak, N., \& Yang, S. T. (2002). Production of galacto-oligosaccharides from lactose by Aspergillus oryzae $\beta$-galactosidase immobilized on cotton cloth Biotechnology and Bioengineering, 77, 8-19.

Aslan, Y., \& Tanriseven, A. (2007). Immobilization of Penicillium lilacinum dextranase to produce isomaltooligosaccharides from dextran. Biochemical Engineering Journal, 34, 8-12.

Bakken, A. P., Hil, C. G., \& Amundson, C. H. (1992). Hydrolysis of lactose in skim milk by immobilized $\beta$-galactosidase (Bacillus circulans). Biotechnology and Bioengineering, 39, 408-417.

Bakken, A. P., Hill, C. G., \& Amundson, C. H. (1991). Use of novel immobilized $\beta$ galactosidase reactor to hydrolyze the lactose constituent of skim milk. II Multiresponse nonlinear regression analysis of kinetic data. Applied Biochemical Biotechnology, 29, 741-756.

Barros, A. L., Almeida, A. M. P., Carvalho, L. B., Jr., \& Azevedo, W. M. (2002) Polysiloxane/PVA-glutaraldehyde hybrid composite as solid phase for immunodetections by ELISA. Brazilian Journal of Medical and Biological Research, 35, 449.

Bayramoglu, G., Yilmaz, M., Senel, A. U., \& Arica, M. Y. (2008). Preparation of nanoficrous polymer grafted magnetic poly(GMA-MMA)-g-MAA beads for immobilization of trypsin via adsorption. Biochemical Engineering Journal, 40, 262-274.

Boon, M. A., Janssen, A. E. M., \& van der Padt, A. (1999). Modelling and parameter estimation of the enzymatic synthesis of oligosaccharides by $\beta$-galactosidase from Bacillus circulans. Biotechnology and Bioengineering, 64, 558-567.

Boon, M. A., Janssen, A. E. M., \& van der Padt, A. (2000). Effects of temperature and enzyme origin on the enzymatic synthesis of oligosaccharides. Enzyme and Microbial Technology, 26, 271-281.

Bruins, M. E., Strubel, M., van Lieshout, J. F. T., Janssen, A. E. M., \& Boom, R. M. (2003) Oligosaccharide synthesis by the hyperthermostable $\beta$-glucosidase from Pyrococcus furiosus: Kinetics and modelling. Enzyme and Microbial Technology, 33, 3-11.

Bruno, L. M., Coelho, J. S., Melo, E. H. M., \& Lima-Filho, J. L. (2005). Characterization of Mucor miehei lipase immobilized on polysiloxane-polyvinyl alcoho magnetic particles. World Journal of Microbiology and Biotechnology, 21 189-192.

Carneiro-Leão, A. M. A., Oliveira, E. A., \& Carvalho, L. B. Jr., (1991). Immobilization of protein on ferromagnetic dacron. Applied Biochemical Biotechnology, 31, 53-56.

Carrara, C. R., \& Rubiolo, A. C. (1996). Determination of kinetics parameters for free and immobilized b-galactosidase. Process Biochemistry, 31, 243-248.

Cavaille, D., \& Combes, D. (1995). Characterization of $\beta$-galactosidase from Kluyveromyces lactis. Applied Biochemical Biotechnology, 22, 55-64.

Dombo, M., Yamamoto, H., \& Nakajima, H. (1997). Production, health benefits and applications of galacto-oligosaccharides. In M. Yalpani (Ed.), Front. Foods food ingredients, 2 (new technologies for healthy foods and nutraceuticals) (pp. 143-156). Mt. Prospect, IL: ATL Press.

Friend, B. A., \& Shahani, K. M. (1982). Characterization and evaluation of Aspergillus oryzae lactase coupled to a regenerable support. Biotechnology and Bioengineering, 24, 329-345. 
Gaur, R., Pant, H., Jain, R., \& Khare, S. K. (2006). Galacto-oligosaccharide synthesis by immobilized Aspergillus oryzae $\beta$-galactosidase. Food Chemistry, 97, 426430.

Hansson, T., Kaper, T., Oost, V. D. J., de-Vos, W. M., \& Adlercreutz, P. (2001) Improved oligosaccharide synthesis by protein engineering of $\beta$-galactosidase CelB from hyperthermophilic Pyrococcus furiosus. Biotechnology and Bioengineering, 73, 203-210.

Huber, R. E., Kurz, G., \& Wallenfels, K. (1976). Quantitation of factors which affect hydrolase and transgalactosylase activities of $\beta$-galactosidase (Escherichia coli) on lactose. Biochemical Journal, 15, 1994-2001.

Iwasaki, K., Nakajima, M., \& Nakao, S. (1996). Galacto-oligosaccharide production from lactose by an enzymatic batch reaction using $\beta$-galactosidase. Process Biochemistry, 31, 69-76.

King, E. L., \& Altman, C. (1956). A schematic method of deriving the rate laws for enzyme-catalyzed reactions. Journal Physical Chemical, 60, 1375-1381.

Kuroiwa, T., Noguchi, Y., Nakajima, M., Sato, S., Mukataka, S., \& Ichikawa, S. (2008). Production of chitosan oligosaccharides using chitosanase immobilized on amylosecoated magnetic nanoparticles. Process Biochemistry, 43, 62-69.

Ladero, M., Santos, A., Garcia, J. L., \& Garcia-Ochoa, F. (2001). Activity over lactose and ONPG of a genetically engineered $\beta$-galactosidase from Escherichia coli in solution and immobilized: Kinetic modelling. Enzyme and Microbial Technology, 29, 181-193.

Mahoney, R. R. (1998). Galactosyl-oligosaccharide formation during lactose hydrolysis: A review. Food Chemistry, 63, 147-154.

Monsan, P., \& Paul, F. (1995). Enzymatic synthesis of oligosaccharides. FEMS Microbiology Letters, 16, 187-192.

Nakkharat, P., \& Haltrich, D. (2006). Lactose hydrolysis anf formation of galactooligosaccharides by a novel immobilized $\beta$-galactosidase from the thermophilic fungus Talaromyces thermophilus. Applied Biochemistry and Biotechnology, 129, 215-225.

Neri, D. F. M., Balcão, V. M., Carneiro-da-Cunha, M. G., Carvalho, L. B., Jr., \& Teixeira, J. A. (2008). Immobilization of $\beta$-galactosidase from Kluyveromyces lactis onto a polysiloxane-polyvinyl alcohol magnetic (mPOS-PVA) composite for lactose hydrolysis. Catalysis Communication, 9, 2334-2339.

Park, H. Y., Kim, H. J., Lee, J. K., Kim, D., \& Oh, D. K. (2007). Galactooligosaccharide production by a thermostable $\beta$-galactosidase from Sulfolobus solfataricus. World Journal of Microbiology and Biotechnology, 24, 1553-1558.

Pieters, B. R., \& Bardeletti, G. (1992). Enzyme immobilization on a low-cost magnetic support: Kinetic studies on immobilized and coimmobilized glucose oxidase and glucoamylase. Enzyme and Microbial Technology, 14, 361-370.

Pimentel, M. C. B., Leao, A. B. F., Melo, E. H. M., Ledingham, W. M., Lima-Filho, J. L., Sivewright, M., et al. (2007). Immobilization of Candida rugosa lipase on Magnetized Dacron: Kinetic study. Artificial Cells, Blood Substitutes, and Biotechnology, 35, 221-235.

Portaccio, M., Stellato, S., Rossi, S., Bencivenga, U., Eldin, M. S., Gaeta, F. S., et al. (1998). Galactose competitive inhibition of $\beta$-galactosidase (Aspergillus oryzae) immobilized on chitosan and nylon supports. Enzyme and Microbial Technology, 23, 101-106.

Sako, T., Matsumoto, K., \& Tanaka, R. (1999). Recent progress on research and applications of non-digestible galacto-oligosaccharides. International Dairy Journal, 9, 69-80.

Schmidt, H., \& Jirstrand, M. (2006). Systems biology toolbox for MATLAB: A computational platform for research in systems biology. Bioinformatics, 22, 514-515.

Shin, H. J., \& Yang, J. W. (1998). Enzymatic production of oligosaccharide by Bullera singularis $\beta$-galactosidase. Journal of Microbiology and Biotechnology, 8, 484-489. Shukla, H., \& Chaplin, M. (1993). Noncompetitive inhibition of $\beta$-galactosidase $(A$. oryzae) by galactose. Enzyme and Microbial Technology, 15, 297-299.

Smith, P. K., Khron, R. I., Hermanson, G. F., Mallia, A. K., Gartner, F. H., Provenzano, M. D., et al. (1985). Measurement of protein using bicinchoninic acid. Analytical Biochemistry, 150, 76-85.

Yang, S. T., \& Okos, M. R. (1989). A new graphical method for determining parameters in Michaelis-Menten-type kinetics for enzymatic lactose hydrolysis. Biotechnology and Bioengineering, 34, 763-773. 